\title{
Methods of Closing Field Experiences in the Study of Irrigation Erosion on the Slope Land in Azerbaijan
}

\author{
RAE Z. H. Aliyev \\ Institute of Soil Science and Agrochemistry of NAS of Azerbaijan, Baku, Azerbaijan
}

Email address:

zakirakademik@mail.ru

To cite this article:

RAE Z. H. Aliyev. Methods of Closing Field Experiences in the Study of Irrigation Erosion on the Slope Land in Azerbaijan. International Journal of Science, Technology and Society. Vol. 6, No. 1, 2018, pp. 13-16. doi: 10.11648/j.jjsts.20180601.13

Received: September 25, 2017; Accepted: October 19, 2017; Published: December 14, 2017

\begin{abstract}
The results of the study clarified the factors responsible for the development of irrigation erosion, where the dependence on the definition of the cross-section of the irrigation groove is determined depending on the water flow and the slopes of the terrain for the conditions of the mountain and foothill zone of Azerbaijan in the example of the Upper Shirvani zone. [3] The equation is derived from the forecast of soil flushing in furrow irrigation. The proposed technique for predicting the flushing of soils during furrow irrigation and the drafting of recommendations for soil irrigation can be used in the design of new areas for agricultural production, mapping of the territory according to the potential danger of manifestation of irrigation erosion and the design of erosion control measures.
\end{abstract}

Keywords: Relief, Irrigation Furrow, Irrigation-Eroded, Undiluted Soils, Phenological Observations, Crop Accounting

\section{Introduction}

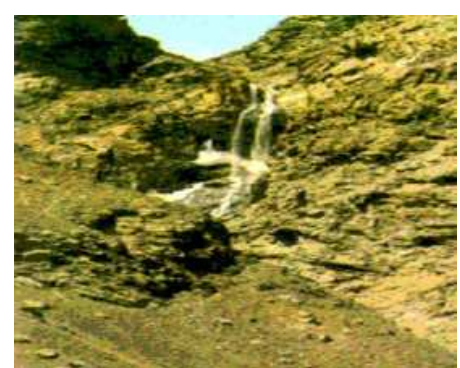

Figure 1. Fragment from the site of the research object.

In irrigated areas in Azerbaijan, the irrigation erosion of the growth of the country's economy causes great damage. The development of mountain and piedmont arrays with noncompliance with erosion control measures, contributes to an increase in the intensity of soil washout, which adversely affects yields and often causes the land to exit from agricultural processing.

Non-compliance with anti-erosion measures causes soil erosion up to $100 \mathrm{t} /$ ha or more during the irrigation season that could ensure the conservation and rational use of land resources, primarily arable land, to carry out measures to protect the soil from water and wind erosion, especially in the southern and eastern regions republic. Currently, the irrigated area in Azerbaijan is 1417 thousand hectares, of which $70 \%$ are located on significant slopes, where they are all more or less susceptible to irrigation erosion. Proceeding from the foregoing, protection of soils, reduction of damage from irrigation erosion are an actual problem, a subject of close attention of many scientists of agrarian science. [2, 11]

Objectives of the study: is the study of the potential danger of irrigation erosion should explore the problems of laying field experiments on the sloping lands of the region to improve the erosion of soils, the development of a set of antierosion measures to restore their fertility for agricultural production, which is extremely necessary to develop additional areas to meet the growing demand of the population, due to cultivation of various types of crops. It should be recognized, when laying and carrying out field experiments with mineral fertilizers on soils that have been confirmed and undergoing erosion, it is necessary to take into account a number of specific features of these soils associated with the effect of erosion processes. On the slopes where there is irrigation erosion of the soil in connection with the irrigation of crops, there are many factors that affect the effectiveness of the fertilizers used and the reliability of field experiments, as well as the formation of the crop. [1, 4]

These include the steepness of the slope, the irrigation 
erosion of the soil, the presence and shape of the clefts in the irrigation furrow, variegation in the distribution of nutrients, and the loss of part of them from the soil and fertilizers due to irrigation erosion.

On soils subject to irrigation erosion, depending on the nature of the slope, their steepness and exposure, in comparison with the flat relief, the thermal regime, the duration of the growing season, the speed of irrigation water in the furrow and the content of food elements along the slope elements, etc., change.

The listed features of the slopes, the peculiarity of erosion processes determine the new methodological requirements for setting and conducting field experiments with fertilizers on eroded soils.

\section{The Course of the Study}

The laying of field experiments with mineral fertilizers should be carried out on weakly-medium and strongly eroded soils and at the same time on the same scheme on washed and non-eroded soils. Depending on the task of field experiments with fertilizers, studies can be conducted on slightly - and medium eroded soils or only on medium - and strongly eroded soils. In all cases, the experiments laid on eroded soil should be accompanied by experiments on the non-eroded soil. But in conditions where there are no uneradiated soils, experiments can be laid on the washed and washed parts of the slope. [3, 4, 5]

Experiments should be conducted in a typical area of the study area, since the selection of the site is the most crucial moment preceding the laying of the experiment.

\section{Progress and Discussion}

This work begins with a preliminary acquaintance with the soil map of the territory of the economy, by which it is established which slopes and eroded soils are characteristic not only for this farm, but also for the area and region in which it is intended to introduce the results of the experiments. A slope of one exposure with washed-out soils of two or three degrees of erosion is selected for the experimental plot, to which is adjoined a flat area (waterrifted) with an unblooded soil (upper even part) and plumewashed soil. ashed and washed slope soils, as well as nonwashed soils according to the genetic profile, should be of the same type. In this case, the slope should be monotonous (straight, convex or concave) and the same exposure. [6,9]

As is known, the processes of irrigation erosion are markedly expressed on the southern slopes, so they should be chosen for experiments. But this does not exclude the possibility of setting up experiments on the northern slopes of other intermediate exposures. [4,9] After selecting the slope, according to the soil map data, the terrain is surveyed in kind. When inspecting the site, the length, steepness and exposure of this slope are specified.

The length of the slope is determined by the magnitude of the attraction between the unclean (upper point) and the soiled (bottom point) soils, measured along a straight line along the slope with a tape or measured steps. The steepness of the slope (angle of inclination) is measured using an ecclesiometer with an accuracy of 0.50 (irrigation erosion begins to appear with 0.50 ). The exposure of the slope is determined with respect to the sides of the light $(\mathrm{C}, \mathrm{CB}, \mathrm{B}$, VU, etc). [3, 4, 5]

When examining the slope in kind, control soil sections (prikopki) are divided to specify (establish) the boundary between the variously washed up soils on the slope. In the definition of erosion, the classification of B. H. Aliyev and Bashirov N. B. is used. In this case, it is necessary to take into account the areas of eroded soil areas in terms of the degree of erosion and washing to mix all the plots of the experiment according to the scheme envisaged. [3, 6]

When placing experiments on the slope, it is necessary to take into account the possible impact of irrigation-eroded processes on the site's experience as a whole or on differently fertilized plots of experience. Individual experiments located on soils with different degrees of erosion should not be placed on the same runoff line in order to avoid transferring soil, as well as nutrients from the upstream slopes to the lower lying ones, with irrigation water. [4] Therefore, the experiment placed on the slope (medium or highly washed soil) must be displaced relative to the experiment laid on the non-washed soil in the left or right side, as shown in Figure 2.

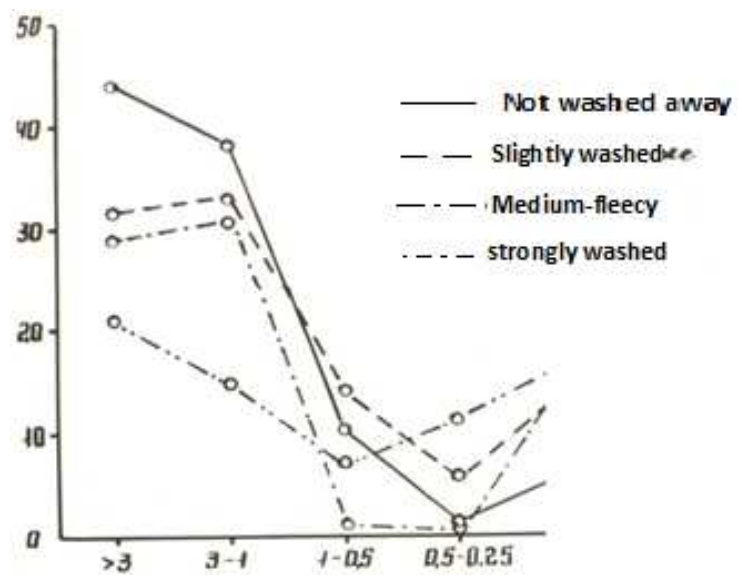

Figure 2. Aggregate composition of the upper horizon of mountain forest soils of various degrees of erosion.

All the main issues related to direct laying and conducting experiments (breaking up the irrigation area, fixing the edge of experience, fertilizing, sowing, plant care, phenological observations, crop accounting, processing of field experiments, documentation and reporting) and recommended for soils of flat areas methodological aids are also acceptable for experiments with soil fertilizers subject to irrigation erosion, with the exception of some surveys and observations of flushing, solid and liquid effluents, water in the furrow, etc., which are set out below. [8]

Consideration of soil washout. The eroding speed of the water flow can be determined from the formula (Averyanov S. F., 1959) and Aliyev B. H.; [1, 2] 


$$
\begin{aligned}
& \mathrm{V} \Delta \mathrm{PW}=1.55 \sqrt{ }(\mathrm{m} 1 \mathrm{~m} 2 \mathrm{~g} / \text { /oh })\left\lfloor(1-\mathrm{p} / 100) \mathrm{dw}\left(\mathrm{j}-\mathrm{j} \_0\right)\right. \\
& (\cos \alpha-\sin \alpha)+1,25 \mathrm{k} \cdot 1 \mathrm{Cw}]
\end{aligned}
$$

Where: $\mathrm{Y} 0 \mathrm{Pw}$ is the eroding soil flow rate for its initial moisture content, $\mathrm{W}, \mathrm{m} / \mathrm{c}^{\wedge}$

$\mathrm{m} 1$ is the coefficient that depends on the presence of data and suspended sediments in the data stream and, according to the data of EE Mirihulava (1970)and Buachidze V. M. [10] respectively, is 0.85 and 1.40 .

$\mathrm{m} 2$ is the coefficient characterizing the effect of the root systems of plants and depends on the content of roots of diameters less than $1 \mathrm{~mm}$;

g-acceleration due to gravity, $\mathrm{m} / \mathrm{s}^{2}$;

$\mathrm{j} 1 \mathrm{j0} 0$, respectively, the specific mass of the solid phase of soil and water, $\mathrm{t} / \mathrm{m} 3$;

$\mathrm{h} 1$ - coefficient characterizing the pulsation of velocities in the flow and equal to 2.3 for the water flow in the irrigation groove;

$\mathrm{P}$ - porosity of aggregates, $\%$;

$\mathrm{dw}$ is the weighted average diameter of water-resistant aggregates after wet sifting of the soil according to Savvinov for a given initial moisture content $\mathrm{W} 2 \mathrm{~m}$;

$a$ is the angle of inclination of the flow channel, deg:

$\mathrm{k}$-coefficient, homogeneity, calculated by the results of the determination of cohesion (Mirikhulova, 1967);

l-coefficient that characterizes the composition of the soil and depends on its bulk mass;

cw-cohesion of soil of initial humidity (according to Tsytovich) after rapid flooding of its surface and saturation to water availability, $\mathrm{t} / \mathrm{m}$;

Taking into account the flushing of the soil during irrigation of cotton and other crops on sloping lands where irrigation erosion occurs, one can determine by the following formula:

$$
\mathrm{Qx}=3 \cdot 1 \cdot 10^{\wedge}(-3) \mathrm{q} \_(\mathrm{x} \text { Bx t2x @ })
$$

Where: Qx - loss of soil from a plot of length $\mathrm{X}, \mathrm{t} / \mathrm{ha}$; qX-average intensity of soil removal through the target X, $\mathrm{g} / \mathrm{cm}$;

Bx-total width of water flows in the $\mathrm{X}$ section, which closes from below the area of 1 hectare, $\mathrm{m}$;

tax-time of transit of water through the target $\mathrm{X}, \mathrm{h}$.

Soil erosion during irrigation erosion can also be calculated from a more simplified formula:

$$
\mathrm{W}=(\mathrm{a}+\mathrm{b}) / 2 \cdot \mathrm{h}:
$$

Where $\mathrm{w}$ is the area of the gully in the section of the furrow profile, $\mathrm{cm}^{2}$

$\mathrm{a}$ is the width of the upper boundary of the gully, $\mathrm{cm}$;

b-width of the bottom of the clefts, $\mathrm{cm}$;

$\mathrm{h}$ - average depth of the gully, $\mathrm{cm}$

for example: $\mathrm{a}=8.5 \mathrm{~cm}: 6=6.5 \mathrm{~cm} ; \mathrm{h}=4.2 \mathrm{~cm}$

the length of the irrigation groove is $50 \mathrm{~m}$ or $5000 \mathrm{~cm}$, then

$$
\mathrm{W}=(8.5+6.5) / 2 \cdot 4.2=31.5 \mathrm{~cm}
$$

Multiplying the area of the gullies in the section of the furrow profile (w) by the furrow length (1), we find the total volume of the washed-out soil from one furrow $50 \mathrm{~m}$ long (in $\mathrm{cm}^{2}$ );

$\mathrm{W} \cdot 1$

Or $\mathrm{W} \cdot 1=5000 \mathrm{x} 31.5=15700 \mathrm{~cm}$, or $0.1517 \mathrm{~m} 3$ of soil washed away with one furrow $50 \mathrm{~m}$ long.

We know that when sowing cotton according to the scheme $60 \times 60$ per 1 ha of arable land there are 166 furrows: consequently, multiplying 166 by $0.1517 \mathrm{~m}$, we find the volume of washed soil from all the furrows with a length of $50 \mathrm{~m}$;

$$
166 \times 0.1575=26.145 \mathrm{~m} .
$$

When translating the volume of washed-out soil in $t /$ ha use formula

$$
\text { A / } 1 \mathrm{k} \cdot \mathrm{V}
$$

Where $\alpha$ is the width of 166 rows, equal to $100 \mathrm{~m}$;

1- the length of the furrow on which the flushing is counted, m;

$\mathrm{k}$ is the volume weight (1.6);

$\mathrm{v}$-volume of soil washed from 166 furrows with a length of $50 \mathrm{~m}, \mathrm{~m} 3$.

Hence, $\alpha / 1 \mathrm{k}+\mathrm{v}=100 / 50 \cdot 1.5 \cdot 26.145 \mathrm{~m} 3=73.206 \mathrm{t} /$ ha

Definition of solid flow. Determination of solid and liquid effluents in the furrowed furrows makes it possible to take into account the washable component of the soil and watersoluble nutrients.

In solid and liquid effluents, humus, gross nitrogen, phosphorus, potassium and their mobile forms are determined, as well as the mechanical composition of the solid runoff. To determine the amount of solid runoff, a slurry is selected at the beginning, not at the end of the furrow at each individual field site, according to the degree of erosion.

Humus in solid runoff is determined according to Tyurin, mechanical composition by pipette method, nitrate nitrogen by the method of Granvald-Liazhu, mobile phosphorus by BP Machigin's method in $1 \%$ carbon-ammonium extract, total nitrogen, phosphorus, by method I M. Malneva and L. P. Gritsenko. $[3,5,7]$

The amount of flushing of the soil, solid runoff and the speed of irrigation water in the furrows is preferably counted in 4-6 times in 4-5 points.

Determination of the speed of water in the furrow.

Determination of the amount and speed of water movement in the furrow (see Figure 3), which shows the ratio of the amount of water to the speed of irrigation flow along the furrow. Since the water velocity in the furrows is directly related to the magnitude of the irrigation jet and the steepness of the slopes: i.e. the steeper the slope, the more it flushes. $[3,4,6]$

The process of irrigation erosion largely depends on the intensity of the water movement in the furrow. As the movement of irrigation water in the furrow accelerates, its destructive effect on the soil increases. [3, 8] 
The speed of water in the furrows is directly related to the magnitude of the irrigation jet and the steepness of the slopes: the steeper the slope, the more intense the flushing.

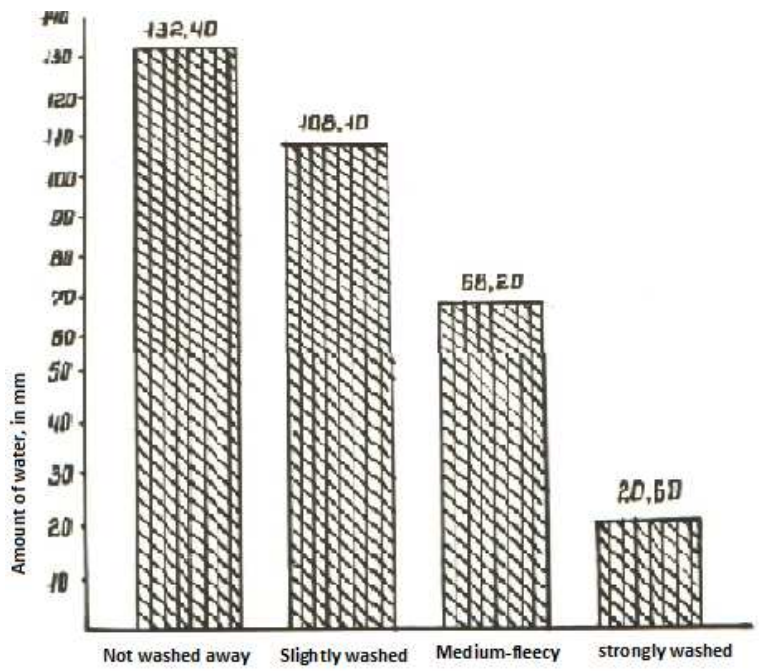

Figure 3. The amount of water flowing to the erosion of 1 aggregate of 3-5 $m$ in the mountain forest brown upper soils.

Consequently, on different elements of the slope, the speed of irrigation water along the furrows is different depending on the slope of the slope. To determine the rates of irrigation water in the furrow are used very primitively: select two or three lengths with different steepness and furrow length.

At the top and bottom of the segment are observers, armed with stopwatches. The observer at the top point of the segment drops the ink powder or liquid oil into the water and gives a command to record the time by stopwatch.

\section{References}

[1] Averyanov S. F. Issues of establishing filtration losses in the irrigation canal system. "Hydrotechnics and Reclamation", b $9,1950$.

[2] Averyanov S. F. On the dynamics of slope flow. Proceedings of the $\mathrm{S}$ All-Union Hydrological Congress, T. P. Gidrometeoizdat, L., 1959.

[3] Aliev B. H, Aliev Z. H Irrigated agriculture in the mountain and foothill regions of Azerbaijan, Baku, "Ziya-Nurlan" 2005.

[4] Aliev B. H. Basics of irrigated agriculture in Azerbaijan. Baku, "Ziya" 2009.

[5] Z. H. Aliyev, A. Djafarov Agroecological assessment and burial of pasture lands of Azerbaijan, Sat. scientific works of the SRI GTM 29th volume Iftu-2009 p. 133-139

[6] Babaev N. H. Irrigation erosion in mountain and foothill areas. Alma-Ata, 1962.

[7] Bashirov N. B. Rational elements of furrow irrigation technique in the conditions of the Shirvan steppe of the Azerbaijan SSR. Proceedings of NIIM, T. KhP, No. 9, Maykop, 1971.

[8] Behbudov A. K. Experimental bases for reclamation of saline lands of the Kura-Araks lowland. Azerb. State Publishing House, Baku, 1977.

[9] Bellman R., Dreyfus S. Applied problems of dynamic programming. M., "Science", 1965.

[10] EE Mirihulava, Buachidze V. M. To the issue of irrigation erosion in Samgori. Tr. Gruz Shigi M, issue 20, 1958.

[11] Mamedov G. Sh. Land reform in Azerbaijan: legal and scientific-environmental issues. Elm Publishing House, Baku2000, pt.372. 